\title{
Undocumented Latina/o Immigrants in Multidisciplinary Settings: Behavioral Health Providers' Role in Promoting Optimal, Ethical Healthcare
}

\author{
Rachel Becker Herbst, Darren R. Bernal, Jonathan Terry \& Brian Lewis \\ University of Miami
}

\begin{abstract}
Undocumented immigrants experience health and treatment disparities exceeding those experienced by other immigrants (Hacker et al., 2011). Behavioral health providers in multidisciplinary medical settings play an integral role in the delivery of services to the 11 million undocumented immigrants residing in the United States, most of whom are Latina/o. Undocumented immigrants face cultural, legal, language, and psychological barriers that affect healthcare access, treatment utilization, and adherence (Achkar \& Macklin, 2009). In the context of these disparities, little consensus exists regarding an ethical decisionmaking process specific to this population. How does a behavioral health provider respond to these dilemmas? This article reviews the changing sociopolitical landscape for the healthcare of undocumented immigrants. Case vignettes highlight and address important ethical issues arising from behavioral health providers' work with this population. We conclude with recommendations regarding the navigation of these ethical challenges and the provision of high quality, accessible healthcare to undocumented immigrants.
\end{abstract}

Keywords: immigrants, Latinas/os, ethics, healthcare, disparities

Successful work with undocumented patients is predicated on behavioral health providers' awareness of the historical, political, legal, and cultural elements impacting undocumented immigrants. Understanding of cultural and contextual stressors that apply to this population will help inform diagnosis and treatment planning. Furthermore, knowledge, skills, and awareness of how to more effectively work with this population are necessary to ameliorate health disparities. This article highlights salient ethical considerations and uses vignettes to illustrate and foster sound ethical decision-making for working with undocumented immigrants in multidisciplinary medical settings. Multidisciplinary settings, where psychologists and other behavioral health providers work collaboratively with other healthcare professionals attending to the emotional as well as physical needs of patients, are becoming increasingly common in today's rapidly evolving landscape of contemporary models for healthcare delivery (Kaslow et al., 2007). 


\section{Overview}

\section{Pertinent History and Demographics}

The U.S. Immigration and Nationality Act of 1965 (1968) signified a legislative move away from national quotas and toward a preference for desired skills and family reunification. This statute eliminated national origin citizenship quotas and paved the way for a substantial number of individuals from Asia and Latin America to immigrate to the U.S. However, this law does not apply to foreign-born family members of legal U.S. residents, and many view the lengthy and costly process of naturalization as unachievable (Sternberg, 2010). Recent estimates indicate that 11 million individuals without legal documentation live in the United States; however, these estimates fluctuate depending on current deportation policies (Nandi et al., 2011). In its first four years, the Obama administration deported 3.2 million undocumented immigrants, or approximately 800,000 per year. This represents a significant decrease from the deportations that occurred during the George W. Bush administration, in which a total of 10.3 million undocumented immigrants, or more than 1.3 million each year, were deported (Vaughan, 2013).

U.S. Census data indicates that undocumented immigrants tend to be employed in jobs characterized by low pay, high turnover, and few or no benefits. Data on nationality indicate that $76 \%$ of these individuals are Latina/o (Vargas Bustamante et al., 2011). This article will predominantly explore issues relevant to Latina/o undocumented immigrants, though many of the ethical concepts may be useful for behavioral health providers with other undocumented individuals. Furthermore, undocumented Latina/o immigrants are a heterogeneous group comprised of different and overlapping cultural, ethnic, and racial identities. Additional considerations will be applicable to specific subpopulations, such as unaccompanied immigrant youth (see for example, Aldarondo \& Becker, 2011), although a discussion of such groups is outside the scope of this paper.

\section{Immigration Laws and Statutes}

Although behavioral health providers are not required to be legal experts, behavioral health providers should be aware of relevant national and local statutes that directly impact their patients. Immigration enforcement has shifted dramatically in the past two decades. The Illegal Immigration Reform and Immigrant Responsibility Act of 1996 (IRRIRA) resulted in an increase in the number of undocumented immigrants detained, as well as an expansion of the types of crimes for which noncitizens could be deported. The Immigration and Customs Enforcement (ICE) was created after September 11 th in the Department of Homeland Security to implement the IRRIRA and manage increased detention and deportation activities. Recent Federal (section 287 (g) agreements of the IRRIRA) and state (e.g., California, Arizona, Georgia) legislation has shifted immigration policy enforcement into the hands of the local police agents (Hacker et al., 2011). State legislation such as California Proposition 187 (later found to be unconstitutional and overturned in federal court) also required publicly funded healthcare facilities to deny care to undocumented immigrants and to report them to the government (Achkar \& Macklin, 2009). These legislative acts have contributed to a perception of nativism, an 
unwelcoming health care environment, and fears that undocumented immigrants will be detained while trying to seek public services (Hacker et al.).

\section{Medical Care and Insurance}

Immigrant utilization of public services is a focal issue in the immigration debate. Despite a sentiment of excluding undocumented immigrants from healthcare reform, three laws include undocumented immigrants and explicitly mandate hospitals' obligations to severely ill or injured patients who arrive at the emergency room (Sanchez et al., 2011). First, the federal Emergency Medical Treatment and Active Labor Act (EMTALA) dictates that, regardless of individuals' legal status or ability to pay, hospital emergency rooms must stabilize patients. Second, Medicaid law manages reimbursements for emergency medical care rendered by hospitals. Third, the Medicare Conditions of Processing forbids hospitals from discharging patients, including undocumented immigrants, without an appropriate post-hospital care plan. Although these three statutes directly influence hospital services for undocumented immigrants, no statutes provide the funding necessary to meet these obligations. Undocumented immigrants represent approximately $20 \%$ of the total uninsured population in the United States. The degree to which this population contributes to uncompensated medical care expenses is unclear, although multiple studies indicate this proportion is less than that of other uninsured groups (Okie, 2007). These issues of compensation may be particularly challenging for behavioral health providers, who already encounter reimbursement difficulties for services rendered in medical settings.

Research demonstrates that social characteristics, including lack of education, poor health status, and living in poverty, transect institutional barriers developed by the health and welfare policies to limit access to necessary health care services (Nandi et al., 2011). Nandi and colleagues reported that undocumented immigrants with an increased time of residence in the United States were better able to navigate the convoluted U.S. healthcare system. In contrast, individuals with lower social capital and lower socioeconomic status were up to six times less likely to report access to health insurance and healthcare. Thus, these undocumented immigrants are particularly vulnerable and require behavioral health providers to consider how best to bridge the service gap created by their reduced ability to access health services.

\section{Healthcare Disparities}

Factors such as low median socioeconomic status and restrictive immigration laws result in healthcare disparities for undocumented immigrants (Martinez et al., 2014). Previous research indicates that undocumented immigrants experience more barriers than documented immigrants in accessing and utilizing medical healthcare services (Nandi et al., 2011) and formal mental health services (Arcury \& Quandt, 2007). This is especially troubling in light of research indicating that having a consistent source of primary and preventative services diminishes racial and ethnic healthcare disparities (Ortega et al., 2007). When undocumented immigrants do utilize healthcare, the type of medical services used

differs from that typically used by citizens, both Latina/o and non-Latina/o. Undocumented 
immigrants typically use hospital outpatient clinics, health centers, and public health clinics (Achkar \& Macklin, 2009). Furthermore disparities appear to persist during care. For example, children whose parents have limited English proficiency are more likely to have decreased access to healthcare, poorer communication with healthcare providers, and greater parental dissatisfaction with healthcare than children in English-speaking families (Flores \& Tomany-Korman, 2008).

Undocumented immigrants do not prefer to use hospital emergency rooms as primary health care, but many reported they had no other option (Vargas Bustamante et al., 2011). Lower outpatient clinic utilization rates and the pattern of primarily seeking medical services in emergency situations speak to the complex healthcare disparities faced by this population (Vargas Bustamante et al.). These healthcare disparities are exacerbated by various factors, including lower levels of social support, the use of passive coping strategies, acculturative stress, low educational attainment, cultural and linguistic difficulties, and poverty (Arcury \& Quandt, 2007).

Though immigrant populations may receive services through Federally Qualified Health Centers (FQHCs), the actual availability of providers in key geographic areas remains minimal. A 2014 editorial in the Fresno Bee highlighted the relative shortage of mental health workers in the immigrant-dense San Joaquin Valley compared to other parts of the state (Anderson, 2014). Though FQHCs may be a primary access point for services even for the uninsured, there is limited evidence to show the extent to which mental health providers are versed in immigrant-specific issues or the ethics of working with these populations. FQHCs may serve as a safety net in many cases, though some non-emergency services and referrals may still be limited by insurance status or require a social security number (Boehm, 2005).

Other safety nets may also fail to catch the undocumented immigrants they intend to serve. For example, in Texas, state mental hospitals are subject to EMTALA (Emergency Medical Treatment and Labor Act), though outpatient follow-up may not always be covered (Texas Comptroller Window on State Government, 2006). In a system that only covers emergency care, immigrants may risk treatment lapses and decompensation between episodes severe enough to warrant resourceintensive emergency stabilization -- episodes that could possibly be reduced through better access to outpatient services.

The intersection of individual and structural factors provides a more comprehensive understanding of the healthcare of undocumented immigrants. In many undocumented immigrant communities, ethnic networks (i.e., family, friends, and neighbors from similar cultural backgrounds) guide individuals toward traditional healthcare services and inform them of deportation risks if they seek medical services outside of the community (Choi, 2009). Despite the information provided by ethnic networks, we posit that a gap exists between legal, enforceable deportation and the fears of deportation, and this gap has ramifications for service utilization. Undocumented immigrants face additional structural challenges to improve their access to treatment because outside forces constrain their decision-making, frame choices, and limit life options (Ortega et al., 2007). 


\section{Ethical Considerations}

The previous section provided foundational information that contextualizes factors such as health status and legal statutes affecting undocumented immigrants. The remainder of this article discusses ethical issues that may arise when behavioral health providers work with undocumented immigrants in multidisciplinary healthcare settings. We first examine components of an ethical decision-making framework, devoting attention to factors affecting this population. We then present three case examples that illustrate these ethical issues. We aim to spark reflection, raise consciousness, and provide behavioral health providers with information that can inform their ethical decision-making process.

\section{Components of Ethical Decision-Making}

Healthcare providers have a moral responsibility to attend to the well-being of the people they serve and for any given profession this responsibility is usually codified in a set of ethical guidelines or principles that all members of that profession are bound to uphold (Beauchamp \& Childress, 2001). Psychologists licensed to practice in the United States are required to be knowledgeable of the American Psychological Association's (APA's) Ethical Principles of Psychologists and Code of Conduct (APA, 2010). APA's Ethical Principles of Psychologists and Code of Conduct (hereinafter referred to as the Ethics Code) consists of General Principles and specific Ethical Standards. The General Principles are aspirational goals to guide behavioral health providers but are not enforceable rules. The Ethical Standards delineate enforceable rules for conduct as behavioral health providers and are written broadly, with the aim of applying to behavioral health providers in varied roles. Psychologists are also expected to utilize sound ethical decision-making that is both consistent with these Principles and Standards and informed by national and local statutes and relevant APA guidelines (Fisher, 2013; Pope \& Vasquez, 2007). Although other potentially applicable codes of ethics exist (e.g., those of the American Counseling Association (2014) or the Association of Black Psychologists (2006), the authors will limit their focus to the Ethics Code, given its universal applicability for psychologists in the U.S. and substantial overlap with other ethical codes for behavioral health providers.

Two Standards encapsulate the primary areas of ethical concern when working with undocumented immigrants: Standard 1.02, "Conflicts Between Ethics and Law, Regulations or Other Governing Legal Authority" and Standard 1.03, "Conflicts Between Ethics and Organizational Demands." Although other aspects of the Ethics Code are applicable, we focus on these Standards because of their broad applicability to behavioral health providers working within multidisciplinary healthcare settings. Therefore, we present a discussion of the highlights and considerations of each Standard and how these Standards may provide conflicting guidance. We further illustrate the applicability of these Standards to ethical considerations during treatment and conclude with vignettes that illustrate these considerations in practice.

Standard 1.02. Standard 1.02 requires behavioral health providers to clarify the nature of the conflict between ethics and the law, regulations, or other governing legal authority, make their 
commitment to the Ethics Code known, and engage in reasonable steps to resolve the conflict, consistent with the Ethics Code. Inherent in the description of this population is the legal status of these individuals. Psychologists need to consider applicability of Standard 1.02 when interacting with members of a vulnerable population who have few resources for seeking healthcare services and fear that utilizing medical services could result in deportation (Achkar \& Macklin, 2009). These deportation fears are associated with increased anxiety, depression, feelings of isolation, and other mental health concerns (Nandi et al., 2011). Furthermore, traumatic immigration journeys (Suarez-Orozco \& SuarezOrozco, 2002) or country of origin trauma histories, such as those experienced by immigrants from countries with a history of political violence (Alegría et al., 2013), may also exacerbate psychological issues. While the legitimacy of these fears may be difficult to substantiate, the effect is palpable and likely affects treatment utilization. Furthermore, behavioral health providers are not law enforcement officers; rather, the Ethics Code mandates behavioral health providers to provide the best possible care to patients, regardless of whether laws are being broken (e.g., patients residing in the U.S. illegally). However, the nuances of providing this care and continuity of healthcare services may necessitate an ethical decision-making process.

Undocumented immigrants frequently report difficulty understanding their health care providers (Ortega et al., 2007), and many attribute the poor quality of healthcare to their accent or English proficiency (Rodríguez, Vargas Bustamante, \& Ang, 2009). While language difficulties may affect multiple non-English speaking populations, potential language difficulties add an additional ethical vulnerability. The Department of Health and Human Services (2010) issued "Guidance and Standards on Language Access Services," provider guidelines that outline a host of "language assistance options" and warn that a liability could occur if a provider requires or suggests that the patient use friends, children, or family members as interpreters. Even if appropriate translation services are available, behavioral health providers promote a patient's ability to comprehend and synthesize information.

Standard 1.03. Standard 1.03 requires behavioral health providers to clarify the nature of the conflict between ethics and the organization with which they are affiliated, make their commitment to the Ethics Code known, and engage in reasonable steps to resolve the conflict, consistent with the Ethics Code. One of the pervading ethical considerations within this Standard pertains to health disparities, which can be perpetuated by organizational policies and procedures that fail to account for the unique needs of vulnerable populations. For example, Principle D of the Ethics Code describes the entitlement of all persons to "access to and benefit from the contributions of psychology and to equal quality in the processes, procedures, and services being conducted by psychologists" (APA, 2010, p. 3). Psychologists strive to uphold this Principle by providing undocumented immigrants access to a multidisciplinary healthcare approach, despite organizational policies and procedures that may differentially curtail their access to these services, as compared with documented patients.

Woven into the ethical considerations in Standard 1.03 is behavioral health providers' potential role in advancing healthcare. As part of the American Psychological Association Strategic Plan, behavioral health providers working in multidisciplinary healthcare settings are urged to educate other health professionals about psychology's role in health, further the application of psychological knowledge in 
diverse healthcare settings, promote psychology's role in diminishing health disparities, and advance the application of psychological knowledge for enhancing overall health and wellness at the individual, organizational, and community levels (APA, 2009). Therefore, behavioral health providers engaged in multidisciplinary care should work with other healthcare providers within their organization to enhance the team's understanding and treatment of undocumented immigrants.

Standard 3.10. Another potential organizational conflict within the multidisciplinary setting centers around confidentiality. Behavioral health providers are required to consider their role as safeguards of information transmission by ensuring that undocumented immigrants comprehend the treatment, as well as the limits and protections of confidentiality, as outlined by Standard 3.10. Given this population's heightened concerns about confidentiality regarding documentation status, behavioral health providers should familiarize themselves with relevant organizational policies to determine their adequacy in protecting undocumented immigrants. Healthcare providers can work with translators to improve healthcare communication (e.g., patient held records), such that this communication is both efficient and confidential (Schoevers, Van den Muijsenbergh, \& Lagro-Janssen, 2009).

\section{Specific Considerations in the Treatment of Undocumented Immigrants}

Behavioral health providers who treat undocumented immigrants must recognize the need to attend to factors impacting the well-being of individuals prior to treatment, during treatment, and following treatment. Additionally, behavioral health providers should utilize a systemic approach, attending to factors impacting health on a more local level as well as on a national or societal level and throughout the course of treatment. Through vignettes presenting ethical considerations that commonly arise in multidisciplinary healthcare settings, we hope to introduce behavioral health providers to a more intimate understanding of challenges faced by undocumented immigrants. Within this framework, behavioral health providers may develop a culturally- and contextually-informed approach to the ethical decision-making process.

\section{Case Vignettes}

The following cases illustrate ethical considerations and their navigation regarding undocumented immigrants' access to and utilization of healthcare in multidisciplinary settings. These vignettes are not intended to be recipes for approaching ethical dilemmas with undocumented immigrants. Rather, they are provided as hypothetical situations that highlight the complexity of the ethical and legal considerations behavioral health providers face when working with this population. Like most complex ethical dilemmas in the profession, the correct course of action for working with undocumented immigrants is rarely a simple question of right versus wrong; indeed, conscientious and well-motivated behavioral health providers may in fact decide on different courses of action in any given situation based upon their own clinical judgment and interpretations of their ethical mandates. For one example of a stepwise model for ethical decision-making, see Pope and Vasquez 
(2007). Though these cases cannot speak to the entirety of barriers encountered and within group heterogeneity, they illustrate some of the financial, language, confidentiality, and other challenges faced by immigrants. At each level, cultural variables and differences may impact how these obstacles are perceived and experienced.

\section{Case 1}

Maria is a 15-year-old Mexican American female with Down Syndrome. Her health care needs are covered by her state's Medicaid system, which has helped her gain access to psychological diagnosis and treatment services. Her parents, who are her primary caregivers, are undocumented Mexican immigrants. Because Maria, who understands English, is the "identified patient," costly translation services are not always employed or offered to the family. Maria's parents do not pursue their own therapeutic services for their emotional needs or to address caregiver burnout resulting from financial difficulties. Maria's parents have grown increasingly frustrated with some of Maria's age-regressed behaviors and their lack of understanding of her treatment plan. The family stops showing for appointments, and Child Protective Services (CPS) is contacted by a well-meaning psychologist. After a CPS worker visits the house, Maria's family grows even more reluctant to engage in her care, voicing fears of investigation, confidentiality, and deportation. Though the case is dismissed by CPS, Maria and her family are lost to follow-up.

This case illustrates dilemmas pertinent to Standard 1.02, particularly concerning legal considerations associated with the National Standards for Culturally and Linguistically Appropriate Services in Health and Health Care (CLAS) Standards (2001) and Medicaid funding requirements. Barriers such as language, ability to contact undocumented immigrants (or their family members/caregivers as seen in this case), and lack of insurance further impinge upon healthcare providers' ability to sustain continuity of care; however, treatment compliance and follow-up services are significant factors in the reduction of health disparities. Healthcare spending for undocumented immigrants has been drastically reduced, sharply impacting funding for follow-up services (Nandi et al., 2011). This case highlights multiple organizational barriers (Standard 1.03) impacting this family's decision to drop out of services. This decision might be further influenced by the stress experienced by an undocumented Latino family raising a child with a disability (Arredondo, Gallardo-Cooper, Delgado-Romero, \& Zapata, 2014), and compounded by a lack of culturally-responsive services (Santiago-Rivera et al., 2011).

\section{Case 2}

An undocumented 13-year-old Honduran American female is seen in an integrated pediatric primary care clinic for increased headaches, stomachaches, and subsequent school refusal. The primary care provider (PCP) has seen this youth and her family on several previous occasions and has provided them with information regarding the specialists' results, which were unremarkable. The mother insists that the PCP conduct more tests; however, the PCP believes she has ruled out all medical causes. Upon consultation with the team psychologist, the daughter discloses symptoms of depression and reports that she has been cutting. The mother confesses that she has also struggled with depression, but begs 
the psychologist to refrain from sharing this information with the PCP or anyone else. Upon exploration of these concerns, the mother describes her fear of being reported for neglect, which she believes will lead to discovery and repercussions of the family's undocumented status. The school had threatened to call social services on the family several years ago when the daughter missed a substantial amount of school. The mother reported that she had kept her daughter home from school for several weeks following the deportation of the father, in part to mourn his loss and also because of the mother's heightened anxiety about the safety of her daughter.

Reflecting on legal considerations outlined in Standard 1.02 leads to a focus on documentation status. Media coverage of increased scrutiny and enforcement of immigration laws causes many undocumented immigrants to refrain from seeking essential medical care and may lead to symptoms of depression, anxiety, and panic attacks (Achkar \& Macklin, 2009). Mindful of these factors and considering organizational policies and procedures (Standard 1.03), the psychologist schedules a follow up appointment in two weeks and contacts the family in the interim via phone, which enables the psychologist to build a close personal relationship with the family (personalismo; Arredondo et al., 2014). Through the strengthening of this relationship, the mother agrees to allow the psychologist to share her documentation status with other providers, therefore enabling the psychologist to collaborate with other providers around the family's complex concerns. The psychologist struggles to connect the family with appropriate outpatient mental health services, due to barriers regarding availability, cost, and language (Arredondo et al.). However, the psychologist partners with an immigrant community center to provide the mother with social support while she and her daughter are placed on a six-month wait list for therapy. The psychologist works with the patient to locate a teacher who she trusts, and subsequently works with the teacher to serve as a bridge to school-based counseling services.

This case demonstrates the importance of harnessing strengths within the provider-patient relationship. Specifically, it demonstrates how behavioral health providers can use the sense of personalismo formed with families to strengthen the relationship between the families and other mental and physical health providers (Cabassa, Lester, \& Zayas, 2007). Additionally, this case represents the use of a reflective process, with keen attention to Standard 1.03, to decide if, how, and when to leverage these relational strengths. It also emphasizes careful attention to psychosocial and contextual stressors that may require flexibility of the integrated care team around issues of informed consent and confidentiality. This case dovetails with research indicating that Latinas/os' help-seeking patterns exist within a social context and are influenced by advice, information, and pressures of close family and friends (Cabassa \& Zayas, 2007). Given these considerations and barriers to care, behavioral health providers can use strengths-based models to promote resilience through various modalities, such as community connectedness, in addition to formal therapy (Arredondo et al., 2014).

\section{Case 3}

In a pediatric primary care clinic, a Mexican teenage mother missed the majority of her 9-month-old son's well-child checks. She frequently brought him to the clinic for sick visits and, when confronted 
by the PCPs and staff about being behind on his vaccinations, apologized and provided them with answers that appeared elusive. The PCP complained to the clinic-based integrated psychologist, adding that the mother is frequently hours late to the clinic when she does arrive for sick visits. The PCP requested that the psychologist assist her in dismissing the family from the clinic and/or calling social services. The psychologist further explored the provider's perspective that the mother did not sufficiently care for her son while ruling out concerns about potential neglect or abuse. The PCP and psychologist decided the psychologist would meet with the family before they jointly decided upon any further action. During the consultation, the mother began to cry as she explained that she and her husband are undocumented immigrants. While pregnant, her husband was driving her to a doctor's appointment when they were pulled over for a minor traffic violation. Because her husband was undocumented and therefore unable to obtain a driver's license, he was arrested and detained for the final three months of her pregnancy. She and the psychologist explored the impact of these traumatic events on her current attempts to seek care for her son. In addition to ongoing fear that she would be detained en route to the PCP's office, the mother expressed fears about putting other family members at risk by asking them to take her and her son to the doctor. Finally, the mother noted that the healthcare system in the U.S. is "confusing and overwhelming" and no one had ever explained the rationale behind the various visits required in the first three years of a child's life.

The psychologist began working with the clinic staff and providers to educate the system of care about the family's struggles and needs while balancing the confidentiality of this family, attending to the legal considerations outlined in Standard 1.02. The mother was provided with various visual educational tools regarding how the clinic, urgent care, and the emergency department work. The mother was given information about the purpose of preventative care that aligns with Medicaid and CLAS Standards (2001) regarding patient communication. The psychologist and mother decided that the mother would reveal her documentation status to a family navigator. The family navigator, whose role is to provide support in systems navigation, provides targeted outreach to the mother, ensuring that she has access to Medicaid-covered transportation, that appointment scheduling is flexible and in Spanish, and that the mother can call to speak with any resource about her healthcare questions.

As evidenced in this case, behavioral health providers are in a unique position to advocate for individuals by serving as the voice of psychological and cultural considerations in the patient's case (APA, 2002; Comas-Díaz, 2011) and promoting healthcare literacy and systems navigation (Arredondo et al., 2014). However, the potential downfalls of such advocacy must be considered, given that advocating may raise ethical issues of confidentiality or cause conflict with organizational policy (Lewis, Arnold, House \& Toporek, 2002).

Taken together, the specific ethical considerations outlined in these vignettes underscore themes behavioral health providers must attend to in order to heal communities and expand our roles in the healthcare landscape. 


\section{A Call to Action}

As highlighted in the preceding vignettes, eradicating health disparities for undocumented immigrants requires transformative change. The Ethical Code, APA's Guidelines on Multicultural Training, Research, Practice, and Organizational Change for Psychologists, and the APA Strategic Plan outline psychologists' ethical obligation to address health disparities, especially in vulnerable populations such as undocumented immigrants. Public health frameworks further underscore the necessity of addressing these disparities, with the understanding that "... to have a healthy community, we can't have a subset of people who don't have access to health care" (Galarneau, 2011, p. 426). The same acknowledgement of the communal nature of well-being has surfaced in political discourse, such as in President Obama's suggestion that undocumented children may need insurance coverage. Galarneau discusses considerations for providing healthcare for undocumented immigrant children:

... because if you've got children who may be here illegally but are still in playgrounds or at schools, and potentially are passing on illnesses and communicable diseases, that aren't getting vaccinated, that I think is a situation where you have to make an exception [to excluding them under the healthcare reform]. (p. 427).

This conflict trickles down to behavioral health providers' practice with undocumented immigrant patients. On one hand, behavioral health providers strive to provide access to their services for all populations. On the other hand, national laws, local statutes, and organizational policies may limit behavioral health providers' ability to realize Ethical Standards. The intersection of these two forces represents a growing potential for ethical dilemmas for behavioral health providers in multidisciplinary healthcare settings, necessitating an understanding of legal and organizational ethical dilemmas and associated action steps. Thus, behavioral health providers' unique training, ethical codes, and ethical principles necessitate they take a reflective, culturally sensitive, advocacyinformed role in the provision of services to undocumented immigrants.

\section{Legal Considerations: Standard 1.02}

Faced with the daunting task of promoting culturally sensitive, holistic healthcare for undocumented immigrants, behavioral health providers must critically examine how hospitals and health centers are currently working to fulfill their medical and ethical obligations. This creative problem solving manifests at various levels, including systems of care interventions, partnering with external organizations, and advocacy. Each of these approaches offer complementary solutions for short- and long-term changes that can improve the access, utilization, and quality of care for undocumented immigrants.

Within the context of current healthcare reform, which includes legal developments like the enactment of the Affordable Care Act (ACA), major shifts have placed an increasing emphasis on the importance of organizational interprofessionalism, integrated models of care, and concepts like the patient-centered medical homes (Beacham, Kinman, Harris, \& Masters, 2012; Kaslow et al., 2007; 
Wilson, Rosensky \& Weiss, 2010). There is an increasing expectation that psychologists and other behavioral health professionals need to be incorporated as active members of healthcare teams not just as outside specialists and consultants.

The information presented above holds implications for any treatment provider, not just behavioral health providers. However, as previously discussed, behavioral health providers may hold particularly advantageous positions for advocating for the needs of undocumented immigrants and reducing barriers to effective, available treatments. Furthermore, as the professional roles of behavioral health providers evolve to keep pace with the changing landscape of healthcare delivery systems, increased opportunities for advocacy agendas emerge.

Creating a larger network of care, including partnerships with community organizations (Arredondo et al., 2014), religious organizations (Caplan et al., 2013), and immigrants' rights groups, enables behavioral health providers to extend and enhance their provision of care to undocumented immigrants beyond limitations created by statutes governing health insurance eligibility. In many undocumented immigrant communities, ethnic networks guide individuals toward traditional healthcare services and inform them of deportation risks if they seek medical services outside of the community (Choi, 2009). Therefore, behavioral health providers can work with agencies, using the agencies' established trust and credibility, to provide outreach and prevention activities targeting these networks, with the aim of identifying and reducing barriers to care and improving adherence. Through these partnerships, behavioral health providers can inform the public that they are not mandated to report immigrants' documentation status to any agency (Santiago-Rivera et al., 2011). These networks also provide undocumented immigrants with an opportunity to interact with behavioral health providers and other professionals in a context beyond that of a traditional visit, thus potentially promoting a sense of personalismo (Santiago-Rivera, Arredondo, \& Gallarado-Cooper, 2002), which enhances the patient-provider relationship and can instill a sense of trust in the healthcare network.

Behavioral health providers can also work to connect patients with public hospitals and clinics, private foundations, and drug manufactures that offer resources to undocumented immigrants. Behavioral health providers must be mindful when consulting with other colleagues, even when discussing potential resources, to provide the least amount of detail needed while recognizing that the nature of services needed and eligibility may be impacted by documentation status (Santiago-Rivera et al., 2011). Behavioral health providers should also recognize that patients might fear being sent to another, unfamiliar system that could place them at risk for discovery of documentation status. This could impact their adherence to these services, future treatment seeking behaviors, and level of fear regarding discovery and deportation (Arcury \& Quandt, 2007). Behavioral health providers can reduce these barriers by providing education on the referral process, with specific information about questions (e.g., documentation status) that will and will not be asked. Additionally, behavioral health providers can reassure patients that they have sent similar families to these services and those families felt comfortable with and benefited from the referrals (Arredondo et al., 2014). Finally, behavioral health providers can provide patients with information about the mission of these organizations, 
which include serving patients regardless of their documentation status or other pertinent factors (e.g., insurance and ability to pay for services; Casas \& Cabrera, 2011).

\section{Organizational Considerations: Standard 1.03}

Behavioral health providers function in a range of practice settings with varying opportunities for collaboration with healthcare professionals like primary care providers. Regardless of whether one is working in a solo practice with only sporadic consultation with a primary care provider or as a fully integrated member of an interdisciplinary care team (Blount, 1998), if the patient is an undocumented immigrant, behavioral health providers should attend to the contextual factors described above. The advantages for those working in more integrated settings, however, are the expanding opportunities for behavioral health providers to play a more integral role in influencing the overall health and wellbeing of these patients through collegial interaction and by participating in interdisciplinary treatment planning (Stone \& Balderrama, 2008).

One real-world example of community partnership is evidenced by the West Coast Mennonite Central Committee, which has established a Victim Service Collaborative (VSC). The VSC is based in Reedley, California, which is an area in the heart of the San Joaquin Valley in California and home to many Latina/o immigrant and migrant families (Public Policy Institute of California, 2004). Through monthly meetings, key community members from school districts, religious organizations, law enforcement, healthcare, and immigration agencies are able to address barriers to access for specific cases, perform shared agency trainings, share resources, and employ best practices (West Coast Mennonite Central Committee, 2013).

A key element to addressing disparities centers around increasing patients' empowerment, or an individual's ability and willingness to manage their health and medical care. Research has supported that undocumented patients infrequently discuss their concerns during medical visits and often refrain from seeking information, while providers generally spend little time informing patients about their treatment plan and often underestimate their patients' desire for information (Nandi et al., 2011). However, higher levels of patient empowerment can enhance satisfaction with care, improve the healthcare process, and potentially improve health outcomes. Patient empowerment may be particularly important for foreign-born patients, as they frequently lack a thorough understanding of the U.S. healthcare system, their treatment, or the role of doctors, which makes them more likely to acquiesce to their providers' decisions (Casas \& Cabrera, 2011). Psychologists' behavioral health knowledge, as well as their commitment to respecting cultural differences, positions them to act as safeguards protecting the rights and welfare of this vulnerable population and empowering undocumented immigrants to better navigate their healthcare (APA, 2002; Lewis et al., 2002). Psychologists and other mental health professionals may be in key positions to understand the barriers to receiving health services, including but not limited to linguistic, financial, logistical, legal, and cultural matters (Martinez \& Carter-Pokras, 2006). 
Due to the barriers with accessing mental health services, one model that has been employed in primary care settings is that of the "warm handoff." In this case, a behavioral health clinician is integrated or co-located to perform brief assessments, interventions, and referrals in a patient's primary care visits. This type of intervention has demonstrated good effectiveness in the VA and other healthcare settings (Tai-Seale, Kunik, Shepherd, Kirchner, \& Gottumukkala, 2010). The Improving Mood: Promoting Access to Collaborative Treatment (IMPACT) model from the University of Washington has also highlighted the many advantages of having integrated mental health services in primary care settings, though much of this research has focused on geriatric, rather than immigrant populations (Unützer et al., 2002). If applied to integrated populations, the emphasis for cultural adaptation and sensitivity cannot be understated (Cardona et al., 2009; Weisman et al., 2005). In pediatric primary care, the family-centered care approach guides behavioral health clinicians to provide appropriate referrals and support for parents as well as children, helping to bridge the gap in families where undocumented parents may refrain from seeking their own source of care (Talmi \& Fazio, 2012).

\section{Moving Forward}

Behavioral health providers who engage in clinical service, research, and advocacy can further the understanding of this population and increase services for them by crafting organizational policies that meet legal standards (e.g., CLAS). For example, research exploring interventions that educate families about the U.S. healthcare systems and empower them to effectively navigate these systems could reduce significant barriers to accessing and utilizing care. Additional focus may be necessary for the most vulnerable among this underserved population (e.g., children, individuals with disabilities, and the elderly). Advocacy efforts, such as pro-bono political asylum evaluations, participation in immigrant-focused community events, and organizational and policy changes, can promote a landscape of quality, culturally-informed systems of care for this vulnerable population (Casas \& Cabrera, 2011; Lewis et al., 2002). However, these advocacy efforts will only create a short-term, piecemeal solution without comprehensive immigration reform and an amendment to the ACA that provides insurance coverage to undocumented immigrants. Integral to this perspective is a careful examination of ethical standards that extend beyond the Western biomedical perspective and embrace the cultural values of Latina/o communities, which will subsequently guide culturallyinformed ethical research, advocacy, and clinical endeavors (Eggerth \& Flynn, 2010). Taken together, these clinical, research, systems, and advocacy efforts of behavioral health providers can create an innovative culture of healthcare for undocumented immigrants. 


\section{Author Contact Information}

Correspondence regarding this article should be directed to: Rachel Becker Herbst, Cincinnati Children's Hospital Medical Center, Behavioral Medicine and Clinical Psychology, 3333 Burnet Ave., MLC 3015, Cincinnati, OH 452293026, Email: rachel.herbst@cchmc.org

Rachel Becker Herbst, Ph.D. is a pediatric psychologist at Cincinnati Children's Hospital Medical Center, collaborating on the development of integrated behavioral health services in pediatric primary care. These universal integrated behavioral health services are provided to all children from birth to age 5 years, with the goal of promoting physical, mental, and behavioral health. Dr. Becker Herbst also is passionate about enhancing the capacity of medical trainees and community partners to provide effective, family-centered health promotion services.

Darren R. Bernal, Ph.D. is an assistant professor of psychology at the University of West Florida. His research examines socioeconomic factors associated with psychological well-being, acculturation, acculturative stress, and mindfulness interventions for enhanced performance. Dr. Bernal's clinical focus is on anxiety, underrepresented groups, immigrants and individuals of low socioeconomic status.

Jonathan Terry, D.O., ABIHM is a board-certified osteopathic physician and surgeon, a general psychiatrist, a Diplomate of the American Board of Psychiatry and Neurology (ABPN), a Diplomate of the American Board of Physicians and Surgeons (NBPAS), and a Diplomate of the American Board of Integrative and Holistic Medicine (ABIHM). Dr. Terry is proud to be a National Health Service Corps Ambassador and works primarily with underserved and migrant worker populations in the San Joaquin Valley of California as well as high-acuity inpatient psychiatric patients. He is also on faculty for medical students and psychology students at several institutions in California.

Brian Lewis, Ph.D. is a health psychologist, board certified in Clinical Health Psychology by the American Board of Professional Psychology. He is an educator and clinician who has been involved in doctoral level training programs in professional psychology for many years, with a primary focus in recent years on training psychologists for new roles in integrated care settings. Dr. Lewis is currently in private practice in Roanoke, VA where he continues involvement in integrated primary care training for doctoral students at Radford University.

\section{References}

Achkar, J. M., R. \& Macklin, R. (2009). Ethical considerations about reporting research results with potential for further stigmatization of undocumented immigrants. Clinical Infectious Diseases, $48,1250-1253$.

Aldarondo, E. \& Becker, R. (2011). Promoting the well-being of unaccompanied immigrant minors. In L. Buki \& L. Piedra (Eds.), Creating infrastructures for Latino mental health (212-231). New York, NY: Springer.

Alegría, M., Fortuna, L. R., Lin, J. Y., Norris, F. H., Gao, S., Takeuchi, D. T., Jackson, J.S., Shrout, P., \& Valentine, A. (2013). Prevalence, risk, and correlates of posttraumatic stress disorder across ethnic and racial minority groups in the United States. Medical Care, 51, 1114-1123. 
American Counseling Association (2014). ACA code of ethics. Retrieved from http://www.counseling.org/resources/aca-code-of-ethics.pdf

American Psychological Association. (2002). Guidelines on multicultural education, training, research, practice, and organizational change for psychologists. Retrieved from http://www.apa.org/pi/oema/resources/policy/multicultural-guideline.pdf

American Psychological Association. (2009). American Psychological Association Strategic Plan. Retrieved from http://www.apa.org/about/apa/strategic-plan/

American Psychological Association. (2010). Ethical principles of psychologists and code of conduct. Retrieved from http://apa.org/ethics/code/index.aspx

Association of Black Psychologists. (2006). Licensure certification proficiency program standards. Retrieved from http://www.abpsi.org/LCPP.html

Anderson, B. (2014). Doctors key to mental health help in Valley. The Fresno Bee. Retrieved from http://www.fresnobee.com/2014/03/29/3850829/doctors-key-to-mental-health-help.html

Arcury, T. A., \& Quandt, S. A. (2007). Delivery of health services to migrant and seasonal farmworkers. Annual Review of Public Health, 28, 345-363. doi:10.1146/annurev.publhealth.27.021405.102106

Arredondo, P., Gallardo-Cooper, M., Delgado-Romero, E., \& Zapata, A. (2014). Culturally responsive counseling with Latinas/os. Alexandria, VA: American Counseling Association.

Beacham, A. O., Kinman, C., Harris, J.G., \& Masters, K. S. (2012). The patient-centered medical home: Unprecedented workforce growth potential for professional psychology. Professional Psychology: Research and Practice, 43, 17-23.

Beauchamp, T., \& Childress, J. (2001). Principle of biomedical ethics (5th ed.). New York: Oxford.

Blount, A. (Ed.) (1998). Integrated Primary Care: The Future of Medical \& Mental Health Collaboration. New York: Norton.

Boehm, D. (2005). The safety net of the safety net: How federally qualified health centers "subsidize" Medicaid managed care. Medical Anthropology Quarterly, New Series 19, 47-63.

Cardona, J.P., Holtrop, K., Cordova, D., Escobar-Chew, A. R., Horsford, S., Tams, L., Villarruel, F., Villalobos, G., Dates, B., Anthony, J. C. Fitzgerald, H. (2009). “Queremos aprender": Latino immigrants' call to integrate cultural adaptation with best practice knowledge in a parenting intervention. Family Process 48, 211-231. 
Cabassa, L., Lester, R., \& Zayas, L. (2007). "It's like being in a labyrinth:" Hispanic immigrants' perceptions of depression and attitudes toward treatments. Journal of Immigrant Health, 9, 116. doi:10.1007/s10903-006-9010-1

Cabassa, L. \& Zayas, L. (2007). Latino immigrants' intentions to seek depression care. American Journal of Orthopsychiatry, 77, 231-242. doi:10.1037/0002-9432.77.2.231

Caplan, S., Escobar, J., Paris, M., Alvidrez, J., Dixon, J., Desai, M., Scahill, L., \& Whittemore, R. (2013). Cultural influences on causal beliefs about depression among Latino immigrants. Journal of Transcultural Nursing, 24, 68-77. doi:10.1177/1043659612453745

Casas, J. M. \& Cabrera, A. P. (2011). Latino/a immigration: Actions and outcomes based on perceptions and emotions or facts? Hispanic Journal of Behavioral Sciences, 33, 283-303. doi:10.1177/0739986311416342

Choi, J. Y. (2009). Contextual effects on health care access among immigrants: Lessons from three ethnic communities in Hawaii. Social Science \& Medicine, 69, 1261-1271.

Comas-Díaz, L. (2011). Multicultural care: A clinician's guide to cultural competence. Washington, DC: American Psychological Association.

Department of Health and Human Services. (2010). Guidance and standards on language access services: Medicare providers. Washington, DC: Government Printing Office.

Eggerth, D. \& Flynn, E. (2010). When the third world comes to the first: Ethical considerations when working with Hispanic immigrants. Ethics and Behavior, 20, 229-242.

Fisher, C. B. (2013). Decoding the ethics code: A practical guide for psychologists ( $3^{\text {rd }}$. ed.). Washington, D.C.: Sage.

Flores, G. \& Tomany-Korman, S. (2008). Racial and ethnic disparities in medical and dental health, access to care, and use of services in US children. Pediatrics, 121, e286-e298.

Galarneau, C. (2011). Still missing: Undocumented immigrants in health care reform. Journal of Health Care for the Poor and Underserved 22, 422-428.

Hacker, K., Chu, J., Leung, C., Marra, R., Pirie, A., Brahimi, M., English, M., Beckmann, J., Acevedo-Garcia, D., \& Marlin, R. P. (2011). The impact of Immigration and Customs Enforcement on immigrant health: Perceptions of immigrants in Everett, Massachusetts, USA. Social Science \& Medicine, 73, 586-594. 
Immigration and Nationality Act of 1965, 79 U.S.C. §§ 202212 et seq. (1968). Retrieved from http://legislink.org/us/pl-89-236

Kaslow, N.J., Bollini, A. M., Druss, B., Glueckauf, L. R., Goldfrank, A., Kelleher, K. J., La Greca, A.M., Varela, R. E., Wang, S. S. H., Weinreb, L., \& Zeltzer, L. (2007). Healthcare for the whole person: Research update. Professional Psychology: Research and Practice, 38, 278-289.

Lewis, J., Arnold, M., House, R., \& Toporek, R. (2002). American Counseling Association Advocacy Competencies. Retrieved from http://www.counseling.org/Publications/

Martinez, I. L. \& Carter-Pokras, O. (2006). Assessing health concerns and barriers in a heterogeneous Latino community. Journal of Health Care for the Poor and Underserved 17, 899-909.

Martinez, O., Wu, E., Sandfort, T., Dodge, B., Carballo-Dieguez, A., Pinto, R., Rhodes, S., Moya, E., \& Chavez-Baray, S. (2014). Erratum to: Evaluating the impact of immigration policies on health status among undocumented immigrants: A systematic review. Journal of Immigrant and Minority Health, 18, 288-288.

Nandi, A., Galea, S., Lopez, G., Nandi, V., Strongarone, S., \& Ompad, D.C. (2011). Access to and use of health services among undocumented Mexican immigrants in a US urban area. American Journal of Public Health, 98, 2011-2020.

Okie, S. (2007). Immigrants and health care - at the intersection of two broken systems. The New England Journal of Medicine, 357, 525-529.

Ortega, A. N., Fang, H., Perez, V. H., Rizzo, J., Carter-Pokras, O., Wallace, S. P., \& Gelberg, L. (2007). Health care access, use of services, and experiences among undocumented Mexicans and other Latinos. Archives of Internal Medicine, 167, 2354-2360.

Public Policy Institute of California. (2004). How is migration changing the Central Valley? 97. San Francisco, CA: Author.

Pope, K. S., \& Vasquez, M. J. T. (2007). Ethics in psychotherapy and counseling: A practical guide ( ${ }^{\text {rd }}$ ed.). San Francisco: Jossey-Bass.

Rodríguez, M. A., Vargas Bustamante, A. \& Ang, A. (2009). Perceived quality of care, receipt of preventive care, and usual source of health care among undocumented and other Latinos. Journal of General Internal Medicine, 24, 508-513.

Sanchez, G. R., Sanchez-Youngman, S., Murphy, A., Goodin, A.S., Santos, R. \& Burciaga Valdez, R. (2011). 
Explaining public support (or lack thereof) for extending health coverage to undocumented immigrants. Journal of Health Care for the Poor and Underserved, 22, 683-699.

Santiago-Rivera, A., Arredondo, P., \& Gallardo-Cooper, M. (2002). Counseling Latinos and la familia. Thousand Oaks, CA: Sage Publications.

Santiago-Rivera, A., Kanter, J., Busch, A., Rusch, L., Reyes, W., West, P., Runge, M. (2011). Latino immigrants with depression: An initial examination of treatment issues at a community clinic. Journal of Immigrant Minority Health, 13, 772-779.

Schoevers, M. A., Van den Muijsenbergh, M. E. T. C. \& Lagro-Janssen, A. L. M (2009). Patient-held records for undocumented immigrants: A blind spot. A systematic review of patient-held records. Ethnicity \& Health, 14, 497-508.

Sternberg, R. B. C. (2010). Transnational mothers crossing the border and bringing their health care needs. Journal of Nursing Scholarship, 43, 64-71.

Stone, L. \& Balderrama, C. (2008). Health inequalities among Latinos: what do we know and what can we do? Health and Social Work, 33, 3-5.

Suarez-Orozco, C., \& Suarez-Orozco, M. (2002). Children of immigration. The developing child series (16165). Cambridge, MA: Harvard University Press.

Tai-Seale, M., Kunik, M. E, Shepherd, A., Kirchner, J., \& Gottumukkala, A. (2010). A case study of early experience with implementation of collaborative care in the Veterans Health Administration. Population Health Management, 13, 331-337.

Talmi, A., \& Fazio, E. (2012). Commentary: Promoting health and well-being in pediatric primary care settings: Using health and behavior codes at routine well-child visits. Journal of Pediatric Psychology, 1, 1-7.

Texas Comptroller Window on State Government (2006). Undocumented immigrants in Texas: A financial analysis of the impact to the state budget and economy. Retrieved from http://www.window.state.tx.us/specialrpt/undocumented/4health.html

Unützer, J., Katon, W., Callahan, C.M., Williams, J. W., Hunkeler, E., Harpole, L., et al. (2002). Collaborative-care management of late-life depression in the primary care setting. JAMA, 288, 2836-2845.

Vargas Bustamante, A., Fang, H., Garza, J., Carter-Pokras, O., Wallace, S. P., Rizzo, J. A., \& Ortega, A. N. 
Volume 8, Number 1, Summer $2016 \quad$ Ethical Care of Undocumented Immigrants - Becker Herbst et al.

(2011). Variations in healthcare access and utilization among Mexican immigrants: The role of documentation status. Journal of Immigrant Minority Health, 14(1), 146-155.

Vaughan, J. (2013). Where are all the deportations? The Washington Times. Retrieved from http://www.washingtontimes.com/news/2013/dec/29/vaughn-what-recorddeportations/?page=all

Weisman, A., Feldman, G., Gruman, C., Rosenberg, R., Chamorro, R., Belozersky, I. (2005). Improving mental health services for Latino and Asian immigrant elders. Professional Psychology: Research and Practice 36, 642-648.

Wilson, S.L., Rosensky, R. H., \& Weiss, J. (2010). The Advisory Committee on Interdisciplinary Community-Based Linkages and the federal role in advocating for interprofessional education. Journal of Allied Health, 39, 210-215.

West Coast Mennonite Central Committee (2013). Restorative Justice. Retrieved from http://westcoast.mcc.org/programs/restorativejustice 